Keisuke Shioji · Toshifumi Mannami · Yoshihiro Kokubo Yoichi Goto · Hiroshi Nonogi · Naoharu Iwai

\title{
An association analysis between ApoA1 polymorphisms and the high-density lipoprotein (HDL) cholesterol level and myocardial infarction (MI) in Japanese
}

Received: 16 February 2004 / Accepted: 10 May 2004 / Published online: 17 July 2004

(C) The Japan Society of Human Genetics and Springer-Verlag 2004

\begin{abstract}
Association studies were performed to confirm the effect of polymorphisms in apolipoprotein A1 (ApoAl) on the high-density lipoprotein cholesterol (HDL-C) level and the incidence of myocardial infarction (MI). A sequence analysis identified nine polymorphisms in ApoA1. After considering linkage disequilibrium, four polymorphisms in ApoAland four polymorphisms in the $5^{\prime}$-flanking regions and $3^{\prime}$-flanking regions from the JSNP database were determined in 1,880 subjects recruited from the Suita study, which represents the general population in Japan. Of the eight polymorphisms tested, the ApoA1 T84C polymorphism had the greatest effect on the levels of HDL-C $\left(P=0.0005, P_{\mathrm{c}}=0.0040\right.$ corrected by the Bonferroni method) and triglyceride $\left(P<0.0001, P_{\mathrm{c}}=0.0008\right)$. The ApoAl MspI polymorphism was not associated with HDL-C or triglyceride levels. We confirmed that the ApoA1 T84C polymorphism was associated with the HDL-C level but not the triglyceride level in patients
\end{abstract}

This study was supported by the Program for the Promotion of Fundamental Studies in Health Science of the Organization for Pharmaceutical Safety and Research of Japan.

K. Shioji $\cdot$ N. Iwai

Department of Epidemiology, Research Institute,

National Cardiovascular Center, Suita, Japan

K. Shioji $(\bowtie)$

Department of Cardiology, Kishiwada City Hospital,

1001 Gakuhara-cho, Kishiwada, Osaka 596-8501,

Japan

E-mail: shiojikeisuke@kpe.biglobe.ne.jp

Tel.: + 81-724-451000

Fax: + 81-724-418809

K. Shioji

The Organization for Pharmaceutical

Safety and Research of Japan, Tokyo, Japan

T. Mannami · Y. Kokubo

Department of Preventive Cardiology,

National Cardiovascular Center, Suita, Japan

Y. Goto $\cdot$ H. Nonogi

Division of Cardiology,

National Cardiovascular Center, Suita, Japan with MI $(n=637)$. Moreover, this polymorphism was associated with the incidence of MI in male subjects $(P=0.0326)$. A logistic analysis indicated that the frequency of $\mathrm{MI}$ in the CC genotype was lower than that in the CT + TT genotype $(P=0.0145, \mathrm{OR}=0.4955,95 \%$ CI: $0.2746-0.8525)$. The ApoAl T84C polymorphism is an important marker for the HDL-C level and may be a new risk marker for MI in Japanese.

Keywords ApoA1 - Polymorphisms · HDL cholesterol $\cdot$ Myocardial infarction $\cdot$ Association study

\section{Introduction}

Lipid profiles are well known to play a pivotal role in the progression of coronary artery disease (CAD): a decreased plasma concentration of high-density lipoprotein cholesterol (HDL-C) and an increased plasma concentration of low-density lipoprotein cholesterol (LDL-C) are associated with the development of CAD (Miller and Miller 1975; Kannel et al. 1979). Apolipoprotein A1 (ApoA1), a component of HDL-C, is a major participant in the regulation of reverse cholesterol transport from peripheral tissues to the liver, and this pathway is thought to help protect against atherosclerosis. In fact, epidemiological studies have reported that decreased plasma concentrations of both HDL-C and ApoA1 were associated with premature CAD (Maciejko et al. 1983).

Genetic factors have been reported to influence the distribution of lipids and lipoprotein levels, including the ApoA1 level (Groenendijk et al. 2001a). A rare variant nonsense mutation at codon 84 has been reported to result in ApoAl deficiency (Matsunaga et al. 1991). Recent epidemiological studies have reported that common ApoAl polymorphisms influence the levels of HDL-C and triglycerides (TG) (Ordovas et al. 1986; Jeenah et al. 1990; Pagani et al. 1990; Talmud et al. 1994; Groenendijk et al. 2001b). In addition, several 
researchers reported associations between ApoA1 polymorphisms and CAD (Karathanasis et al. 1983; Ordovas et al. 1986; Reguero et al. 1998), whereas others found no positive association (Ordovas et al. 1991; Marshall et al. 1994; Yamada et al. 2002). One possible reason for the inconsistencies among previous association studies may be that almost all of these studies considered only a few restriction fragment-length polymorphisms instead of every polymorphism in the ApoAlgene. Thus, the polymorphism that has the greatest effect on the HDL-C level and the incidence of CAD may have been missed in previous studies.

To evaluate the effects of polymorphisms in ApoAl on lipid levels, we sequenced the ApoAl gene and conducted an association study using a large cohort (the Suita population $n=1,880$ ), representing the general population in Japan. In addition, we confirmed an association between ApoAl polymorphisms and lipid levels. Finally, we investigated the association between the ApoAl polymorphism and the incidence of myocardial infarction (MI) using patients with MI $(n=637)$.

\section{Subjects and methods}

\section{Subjects}

The Suita population The selection criteria and design of the Suita study have been described previously (Mannami et al. 1997; Shioji et al. 2004a). Genotypes were determined in 1,880 consecutive subjects who visited the National Cardiovascular Center between April 2002 and February 2003 (867 men, 1,013 women). The characteristics of this population are shown in Table 1.

Table 1 Characteristics of the Suita population. $P$ value was calculated by the Student's $t$ test. $B M I$ body mass index, $T C$ total cholesterol, $H D L-C$ high-density lipoprotein cholesterol, $L D L-C$ low-density lipoprotein cholesterol, $T G$ triglyceride, $\% C V A$ percentage of subjects with cerebrovascular accident, $\% O M I$ percentage of subjects with old myocardial infarction, $\% H T$ percentage of subjects with hypertension, $\% D M$ percentage of subjects with diabetes mellitus, $\% H L P$ percentage of subjects with hyperlipidemia, \%drinking percentage of subjects with a drinking habit, $\%$ smoking percentage of subjects with a smoking habit

\begin{tabular}{lccr}
\hline Parameter & Male & Female & $P$ value \\
\hline$n$ & 867 & 1,013 & \\
Age (year) & $66.3 \pm 0.4$ & $63.3 \pm 0.3$ & $<0.0001$ \\
BMI (kg/m $\left.{ }^{2}\right)$ & $23.2 \pm 0.1$ & $22.3 \pm 0.1$ & $<0.0001$ \\
TC (mmol/l) & $5.13 \pm 0.03$ & $5.58 \pm 0.02$ & $<0.0001$ \\
HDL-C (mmol/l) & $1.43 \pm 0.01$ & $1.68 \pm 0.01$ & $<0.0001$ \\
TG (mmol/l) & $1.38 \pm 0.03$ & $1.07 \pm 0.03$ & $<0.0001$ \\
Blood glucose (mmol/l) & $5.74 \pm 0.04$ & $5.30 \pm 0.04$ & $<0.0001$ \\
\%CVA & 3.6 & 1.4 & 0.0018 \\
\%OMI & 2.1 & 0.5 & 0.0015 \\
\%HT & 45.9 & 37.2 & $<0.0001$ \\
\%DM & 11.4 & 4.5 & $<0.0001$ \\
\%HLP & 14.8 & 24.0 & $<0.0001$ \\
\%Drinking & 67.0 & 29.5 & $<0.0001$ \\
\%Smoking & 29.9 & 6.3 & $<0.0001$ \\
\hline
\end{tabular}

When the association between the ApoA1 T84C polymorphism and the incidence of myocardial infarction was analyzed, subjects with ischemic heart disease were excluded.

The myocardial infarction (MI) group The selection criteria and design of the MI group have been described previously (Takagi et al. 2002). This group consisted of randomly selected inpatients and outpatients with documented MI ( $n=637,547$ men and 90 women) who were enrolled in the Division of Cardiology at the National Cardiovascular Center between May 2001 and April 2003 and met the following criteria: (1) chest pain of $\geq 30 \mathrm{~min}$ duration; (2) electrocardiographic ST segment elevation of $\geq 0.1 \mathrm{mV}$ in two or more leads in the same vascular territory; and (3) subsequent elevation of creatine phosphokinase levels to more than twice the normal range.

Written informed consent was obtained from every subject after a full explanation of the study, which was approved by the Ethics Committee of the National Cardiovascular Center and by the Committee on Genetic Analysis and Genetic Therapy of the National Cardiovascular Center.

\section{DNA studies}

The promoter region (up to $-1 \mathrm{~kb}$ ) and all of the exonic regions in ApoAl were sequenced for polymorphisms

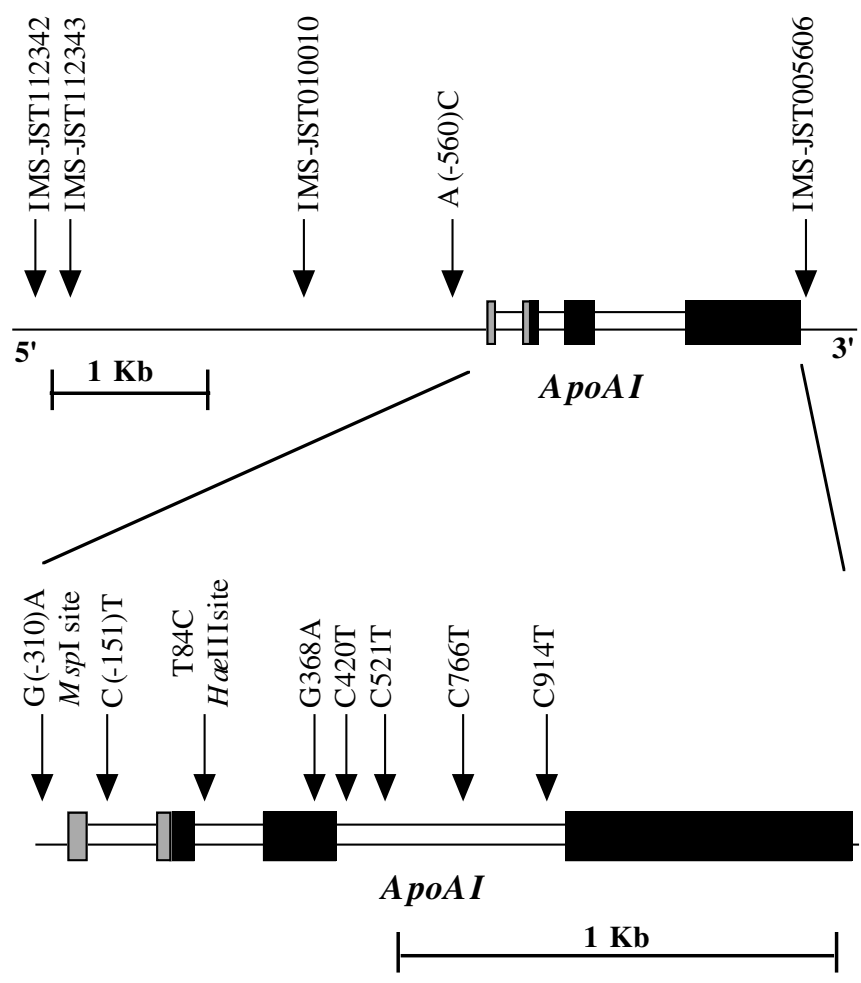

Fig. 1 Schema of the ApoAl gene and the positions of the determined polymorphisms. Gray and black boxes indicate the $5^{\prime}$ untranslated and coding regions, respectively 
in 36 subjects (Fig. 1). For the 5'-flanking regions and 3 '-flanking regions, we selected four polymorphisms for genotyping from a public database (JSNP, http:// www.snp.ims.u-tokyo.ac.jp, Fig. 1) (Hirakawa et al. 2002). The ApoE and ATP-binding cassette transporter A1 (ABCA1) $\mathrm{G}(-273) \mathrm{C}$ polymorphisms were also determined as previously described (Shioji et al. 2004b). $A p o E$ polymorphisms were categorized into three genotypes: E2 ( $\epsilon 2 / \epsilon 2+\epsilon 2 / \epsilon 3+\epsilon 2 / \epsilon 4$ subjects), E3 ( $\epsilon 3 / \epsilon 3$ subjects), E4 ( $\epsilon 3 / \epsilon 4+\epsilon 4 / \epsilon 4$ subjects) (Lefevre et al. 1997; Shioji et al. 2004b). All polymorphisms were determined by the TaqMan system. The primer and probe sequences are available on request.

\section{Statistical analysis}

Values are expressed as mean \pm standard error of the mean (SEM). For TG values, while a logarithmic transformation was applied for the statistical test, untransformed values are shown in the table. LDL-C was calculated by Friedewald's formula $[($ LDL-C $)=($ total cholesterol, TC)-(HDL-C)-(TG/5). We excluded those whose HDL-C or TG levels were $\geq 2.6 \mathrm{mM}$ or $4.53 \mathrm{mM}$, respectively]. All statistical analyses were performed with the JMP statistical software package (SAS Institute, Inc.). Values of $P<0.05$ were considered to indicate statistical significance. Multiple linear regression and multiple logistic analyses were performed with other covariates. The residual levels were calculated by adjusting for covariates. Differences in numerical data among the groups were evaluated by Student's $t$ test or one-way analysis of variance (ANOVA). Hardy-Weinberg equilibrium was calculated by a chi-square test. To measure linkage disequilibrium (LD) between polymorphisms, $D^{\prime}$ and $r^{2}$ values were analyzed using the SNPAlyze statistical software package (Dynacom, Inc.). In some settings, the $P$ values were corrected $\left(P_{\mathrm{c}}\right)$ by multiplying by 8 (eight polymorphisms, Bonferroni).

\section{Results}

Polymorphisms of the promoter and exonic regions in ApoAl

We found two polymorphisms in the promoter region, one in intron 1 , one in intron 2 , one in exon 3 , and four in intron 3 (Table 2 and Fig. 1).

LD was evaluated by calculating $r^{2}$ values (Table 3 ). We regarded $r^{2}>0.25$ as tight linkage. Accordingly, we selected four polymorphisms, G(-310)A, T84C, G368A, and C420T, for the following association study. The $\mathrm{G}(-310) \mathrm{A}$ and $\mathrm{T}(84) \mathrm{C}$ polymorphisms correspond to the MspI (Pagani et al. 1990; Tuteja et al. 1992) and HaeIII (Groenendijk et al. 2001b) polymorphisms, respectively. The G368A polymorphism was accompanied by a missense mutation (GCC $\rightarrow$

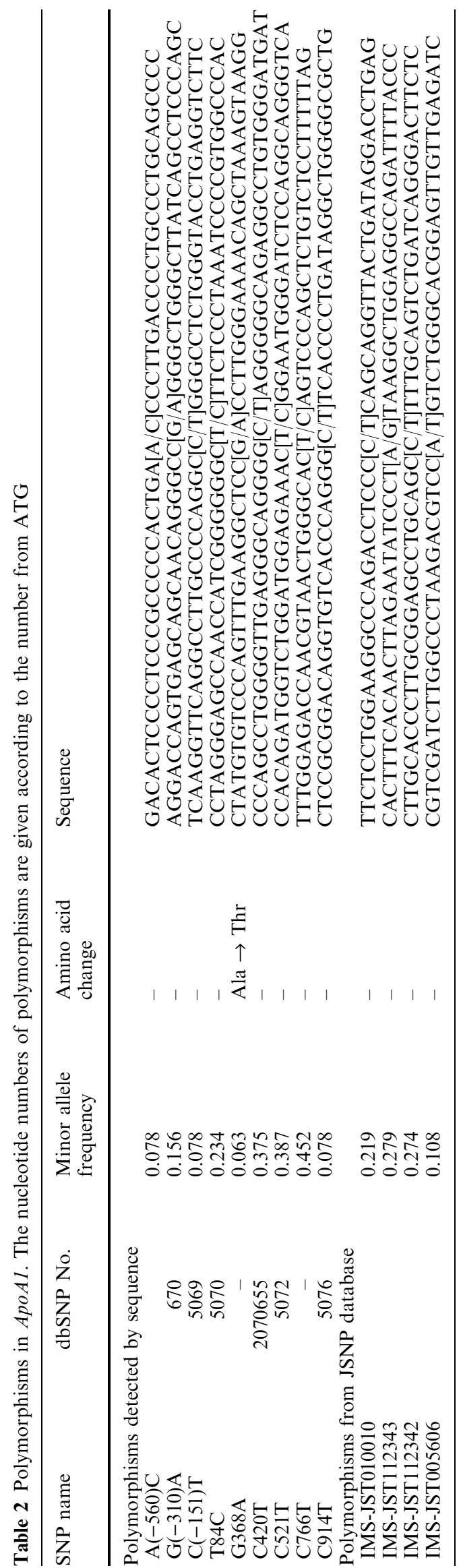


Table 3 Linkage disequilibrium among the polymorphisms in ApoA1. $R^{2}$ values are shown, $R^{2}$ values described are based on the genotypes of 36 subjects used for sequence analyses. All values refer to the variant allele indicated in the table

\begin{tabular}{|c|c|c|c|c|c|c|c|c|c|}
\hline & $\mathrm{A}(-560) \mathrm{C}$ & $\mathrm{G}(-310) \mathrm{A}$ & $\mathrm{C}(-151) \mathrm{T}$ & $\mathrm{T} 84 \mathrm{C}$ & G368A & $\mathrm{C} 420 \mathrm{~T}$ & $\mathrm{C} 521 \mathrm{~T}$ & $\mathrm{C} 766 \mathrm{~T}$ & C914T \\
\hline$A(-560) C$ & & 0.016 & 1 & 0.277 & 0.006 & 0.051 & 0.044 & 0.084 & 1 \\
\hline $\mathrm{G}(-310) A$ & & & 0.016 & 0.057 & 0.004 & 0.111 & 0.121 & 0.158 & 0.016 \\
\hline $\mathrm{C}(-151) \mathrm{T}$ & & & & 0.277 & 0.006 & 0.051 & 0.044 & 0.084 & 1 \\
\hline $\mathrm{T} 84 \mathrm{C}$ & & & & & 0.020 & 0.184 & 0.184 & 0.002 & 0.277 \\
\hline G368A & & & & & & 0.040 & 0.044 & 0.057 & 0.006 \\
\hline $\mathrm{C} 420 \mathrm{~T}$ & & & & & & & 1 & 0.767 & 0.051 \\
\hline C521T & & & & & & & & 0.767 & 0.044 \\
\hline $\mathrm{C} 766 \mathrm{~T}$ & & & & & & & & & 0.084 \\
\hline C914T & & & & & & & & & \\
\hline
\end{tabular}

Table 4 Lipid levels among the ApoA1 T84C genotypes (Suita population). We excluded subjects who were receiving hypolipidemic medication. Values are mean \pm SEM, Res. TC, Res. HDLC, Res. LDL-C, and Res. TG were adjusted for gender, age, BMI, smoking (cigarettes/day), and alcohol consumption (ethanol $\mathrm{ml} /$ week). $P$ value was calculated by ANOVA. $P$ values were corrected $\left(P_{\mathrm{c}}\right)$ by multiplying by 8 (eight polymorphisms, Bonferroni). BMI body mass index, $\% H T$ percentage of subjects with hypertension,
$\% D M$ percentage of subjects with diabetes mellitus, $\% H L P$ percentage of subjects with hyperlipidemia, $T C$ total cholesterol, $H D L-C$ high-density lipoprotein cholesterol, $L D L-C$ low-density lipoprotein cholesterol, $T G$ triglyceride, Res. $T C$ residuals of TC; Res. $H D L-C$ residuals of HDL-C, Res. $L D L-C$ residuals of LDL-C, Res. $T G$ residuals of TG; \%drinking percentage of subjects with a drinking habit; \%smoking percentage of subjects with a smoking habit

\begin{tabular}{|c|c|c|c|c|c|}
\hline ApoA1 T84C genotype & $\mathrm{TT}$ & $\mathrm{TC}$ & $\mathrm{CC}$ & $P$ value & $P_{\mathrm{c}}$ value \\
\hline Number (males/females) & $469 / 487$ & $279 / 310$ & $48 / 42$ & 0.5378 & \\
\hline Age (years) & $63.8 \pm 0.4$ & $63.9 \pm 0.5$ & $65.5 \pm 1.2$ & 0.3890 & \\
\hline BMI $\left(\mathrm{kg} / \mathrm{m}^{2}\right)$ & $22.7 \pm 0.1$ & $22.6 \pm 0.1$ & $22.4 \pm 0.3$ & 0.7253 & \\
\hline$\% \mathrm{HT}$ & 37.6 & 37.2 & 48.9 & 0.0977 & \\
\hline$\% \mathrm{DM}$ & 6.5 & 7.3 & 10 & 0.4527 & \\
\hline$\%$ HLP & 41.6 & 42.8 & 33.3 & 0.2307 & \\
\hline $\mathrm{TC}(\mathrm{mmol} / \mathrm{l})$ & $5.32 \pm 0.03$ & $5.39 \pm 0.03$ & $5.27 \pm 0.09$ & 0.2325 & 1 \\
\hline HDL-C (mmol/l) & $1.54 \pm 0.01$ & $1.59 \pm 0.02$ & $1.68 \pm 0.04$ & 0.0005 & 0.0040 \\
\hline LDL-C $(\mathrm{mmol} / \mathrm{l})^{\mathrm{a}}$ & $3.24 \pm 0.02$ & $3.29 \pm 0.03$ & $3.16 \pm 0.08$ & 0.2357 & 1 \\
\hline $\mathrm{TG}(\mathrm{mmol} / \mathrm{l})^{\mathrm{b}}$ & $1.26 \pm 0.03$ & $1.15 \pm 0.04$ & $0.95 \pm 0.09$ & $<0.0001$ & 0.0008 \\
\hline Res. TC (mmol/l) & $-0.02 \pm 0.03$ & $0.03 \pm 0.03$ & $-0.05 \pm 0.08$ & 0.3332 & 1 \\
\hline Res. HDL-C (mmol/l) & $-0.03 \pm 0.01$ & $0.02 \pm 0.01$ & $0.12 \pm 0.04$ & 0.0002 & 0.0016 \\
\hline Res. LDL-C $(\mathrm{mmol} / \mathrm{l})^{a}$ & $-0.01 \pm 0.02$ & $0.03 \pm 0.03$ & $-0.07 \pm 0.08$ & 0.3235 & 1 \\
\hline Res. TG $(\mathrm{mmol} / \mathrm{l})^{\mathrm{b}}$ & $0.05 \pm 0.03$ & $-0.05 \pm 0.03$ & $-0.24 \pm 0.09$ & $<0.0001$ & 0.0008 \\
\hline$\%$ Drinking & 47.7 & 47.9 & 55.6 & 0.3550 & \\
\hline$\%$ Smoking & 18.3 & 20.0 & 13.3 & 0.2688 & \\
\hline
\end{tabular}

aThe formula for calculating LDL-C is described in "Subjects and methods", and we excluded subjects whose HDL-C or TG levels were $\geq 2.6 \mathrm{mM}$ or $4.53 \mathrm{mM}$, respectively $(\mathrm{TT}, n($ male/female $)=457 / 478: \mathrm{TC}, n=274 / 301: \mathrm{CC}, n=48 / 41)$

${ }^{\mathrm{b}}$ Test performed on log-transformed values

ACC, Ala $\rightarrow$ Thr) at codon 61 in exon 4 (Matsunaga et al. 1991).

\section{Association study of ApoA1 (Suita population)}

The T84C polymorphism had the greatest effect on the levels of HDL-C and TG, but not the levels of TC and LDL-C, among the eight polymorphisms (sample power $=0.96, \alpha$ value $=0.05$, two-tailed, Table 4 ). The IMSJST112342 and IMS-JST112343 polymorphisms were associated with the levels of HDL-C and TG (residuals of HDL-C, $P=0.0059, P_{\mathrm{c}}=0.0472$, each: residuals of TG, $P=0.0002, P_{\mathrm{c}}=0.0016$, each). The other polymorphisms were not associated with HDL-C or TG levels. The IMS-JST112342 polymorphism was in almost complete linkage with the IMS-JST112343 polymorphism $\left(r^{2}=0.98157, D^{\prime}\right.$ value $\left.=1, P<0.0001\right)$. The IMSJST112342 and IMS-JST112343 polymorphisms were in tight linkage with the T84C polymorphism $\left(r^{2}=0.41365\right.$, $D^{\prime}$ value $=0.71155, P<0.0001$, each). Accordingly, the effects of the IMS-JST112342 and IMS-JST112343 polymorphisms may be mainly explained by their linkage with the T84C polymorphism. We previously reported that the $A p o E$ genotype and the $A B C A 1$ $\mathrm{G}(-273) \mathrm{C}$ effect the HDL-C level (Shioji et al. 2004b). Accordingly, we performed the multiple logistic analysis, which included gender, age, body mass index (BMI), smoking, alcohol consumption, ApoE genotype, $A B C A 1$ $\mathrm{G}(-273) \mathrm{C}$, and ApoA1 T84C. As shown in Table 5, the multiple logistic analysis indicated that $A p o E$ genotype, ApoA1 T84C, and $A B C A 1 \mathrm{G}(-273) \mathrm{C}$ were independent factors significantly associated with the HDL-C level. No significant deviation from the Hardy-Weinberg equilibrium was observed in the T84C polymorphism $(P=0.8075)$. Thus, we selected the T84C polymorphism for the following association study.

Association among ApoA1 T84C and lipid profile (the MI group)

To confirm the association between the ApoAl T84C polymorphism and the levels of HDL-C and TG, we 
Table 5 Sum of square and $F$ value of high-density lipoprotein cholesterol (HDL-C) from multiple logistic analyses. BMI body mass index, $A B C A 1$ ATP-binding cassette transporter $\mathrm{A} 1$ gene

\begin{tabular}{lrrr}
\hline Source & $\begin{array}{l}\text { Sum of } \\
\text { squares }\end{array}$ & $F$ value & Probability $>F$ \\
\hline BMI & 31,815 & 171.5 & $<0.0001$ \\
Gender & 18,881 & 101.7 & $<0.0001$ \\
Alcohol consumption & 13,588 & 73.2 & $<0.0001$ \\
$\quad$ (ethanol ml/week) & & & \\
ApoE genotype & 4,360 & 11.7 & $<0.0001$ \\
ApoA1 T84C & 2,981 & 8.0 & 0.0003 \\
Smoking (cigarettes/day) & 1,972 & 10.6 & 0.0011 \\
Age & 1,761 & 9.5 & 0.0021 \\
ABCA1 G(-273)C & 1,475 & 4.0 & 0.0190 \\
\hline
\end{tabular}

Table 6 Lipid levels among the ApoA1 T84C genotypes [miocardial infarction (MI) group]. Values are expressed as the mean \pm SEM. $P$ value was calculated by ANOVA. BMI body mass index, $\% H T$ percentage of subjects with hypertension, $\% D M$ percentage of subjects with diabetes mellitus, $\% H L P$ percentage of subjects with hyperlipidemia, $T C$ total cholesterol, $H D L-C$ high-density lipoprotein cholesterol, $L D L-C$ low-density lipoprotein cholesterol, $T G$ triglyceride

\begin{tabular}{lllll}
\hline $\begin{array}{l}\text { ApoA1 T84C } \\
\text { genotype }\end{array}$ & TT & TC & CC & $P$ value \\
\hline $\begin{array}{l}\text { Number } \\
\text { (males/females) }\end{array}$ & $326 / 61$ & $204 / 27$ & $17 / 2$ & 0.3264 \\
Age (years) & $62.1 \pm 0.5$ & $62.4 \pm 0.7$ & $60.2 \pm 2.4$ & 0.6632 \\
BMI (kg/m $\left.{ }^{2}\right)$ & $23.7 \pm 0.2$ & $23.7 \pm 0.2$ & $24.7 \pm 0.7$ & 0.3780 \\
\%HT & 55.8 & 55.2 & 42.1 & 0.5076 \\
$\%$ DM & 47.1 & 37.2 & 31.6 & 0.0439 \\
\%HLP & 55.5 & 60.2 & 52.6 & 0.4844 \\
TC (mmol/l) & $5.18 \pm 0.06$ & $5.30 \pm 0.07$ & $5.21 \pm 0.24$ & $0.2752^{\mathrm{a}}$ \\
HDL-C (mmol/1) & $1.09 \pm 0.02$ & $1.11 \pm 0.03$ & $1.35 \pm 0.08$ & $0.0050^{\mathrm{a}}$ \\
LDL-C (mmol/l) & $3.34 \pm 0.06$ & $3.47 \pm 0.07$ & $3.57 \pm 0.25$ & $0.2252^{\mathrm{a}, \mathrm{b}}$ \\
TG (mmol/l) & $1.48 \pm 0.05$ & $1.53 \pm 0.06$ & $1.21 \pm 0.21$ & $0.2872^{\mathrm{c}}$ \\
\hline
\end{tabular}

${ }^{\mathrm{a}}$ Test performed on residual values adjusted for gender, age, and BMI

${ }^{\mathrm{b}}$ The formula for calculating LDL-C is described in "Subjects and methods", and we excluded subjects whose HDL-C or TG levels were $\geq 2.6 \mathrm{mM}$ or $4.53 \mathrm{mM}$, respectively [TT, $n$ (male/female $)=322 /$ 61: TC, $n=202 / 27:$ CC, $n=16 / 2$ ]

${ }^{c}$ Test performed on log-transformed residual values adjusted for gender, age, and BMI

determined the genotypes in the MI group. The T84C polymorphism was associated with the HDL-C level but not the TG level (Table 6). The T84C polymorphism also affected the prevalence of diabetes mellitus (DM, $P=0.0439$ ). No significant deviation from the HardyWeinberg equilibrium was observed in the MI group $(P=0.2403)$. Thus, a positive association was observed between the T84C polymorphism and the HDL-C level in two groups: the Suita population and the MI group.

Association between ApoA1 T84C and incidence of MI

We next evaluated whether the ApoA1 T84C polymorphism was associated with the incidence of MI. Since the MI group and the Suita population were not matched
Table 7 Association between the ApoA1 T84C polymorphism and the incidence of myocardial infarction (MI). All subjects are male. Values are expressed as the mean \pm SEM. Control Suita subjects without ischemic heart disease, $M I$ patients with myocardial infarction, $B M I$ body mass index, $\% H T$ percentage of subjects with hypertension, $\% D M$ percentage of subjects with diabetes mellitus, $\% H L P$ percentage of subjects with hyperlipidemia, TC total cholesterol, $H D L-C$ high-density lipoprotein cholesterol, $L D L-C$ low-density lipoprotein cholesterol, $T G$ triglyceride

\begin{tabular}{|c|c|c|c|}
\hline & Control & MI group & $P$ value \\
\hline Number & 806 & 547 & \\
\hline Age (years) & $65.8 \pm 0.4$ & $60.8 \pm 0.4$ & \\
\hline BMI $\left(\mathrm{kg} / \mathrm{m}^{2}\right)$ & $23.3 \pm 0.1$ & $23.8 \pm 0.1$ & $0.0003^{\mathrm{a}}$ \\
\hline$\% \mathrm{HT}$ & 44.7 & 54.3 & $0.0003^{\mathrm{a}}$ \\
\hline$\% \mathrm{DM}$ & 11.1 & 41.6 & $<0.0001^{\mathrm{a}}$ \\
\hline$\% \mathrm{HLP}$ & 40.6 & 57.9 & $<0.0001^{\mathrm{a}}$ \\
\hline $\mathrm{TC}(\mathrm{mmol} / \mathrm{l})$ & $5.14 \pm 0.03$ & $5.16 \pm 0.04$ & $0.3168^{\mathrm{b}}$ \\
\hline $\begin{array}{l}\mathrm{HDL}-\mathrm{C} \\
(\mathrm{mmol} / \mathrm{l})\end{array}$ & $1.43 \pm 0.01$ & $1.08 \pm 0.02$ & $<0.0001^{\mathrm{b}}$ \\
\hline $\begin{array}{l}\text { LDL-C } \\
(\mathrm{mmol} / \mathrm{l})\end{array}$ & $3.10 \pm 0.03$ & $3.34 \pm 0.04$ & $<0.0001^{\mathrm{b}, \mathrm{c}}$ \\
\hline $\begin{array}{l}\mathrm{TG}(\mathrm{mmol} / \mathrm{l}) \\
\text { ApoA1 T84C }\end{array}$ & $1.40 \pm 0.04$ & $1.54 \pm 0.05$ & $0.0641^{\mathrm{d}}$ \\
\hline $\mathrm{TT} / \mathrm{TC} / \mathrm{CC}$ & $\begin{array}{l}477 / 280 / 49 \\
59.2 \% / 34.7 \% / 6.1 \%\end{array}$ & $\begin{array}{l}326 / 204 / 17 \\
59.6 \% / 37.3 \% / 3.1 \%\end{array}$ & $0.0326^{\mathrm{a}}$ \\
\hline
\end{tabular}

${ }^{\mathrm{a}}$ The distributions in the Suita population and patients with MI were compared by the chi-square test

${ }^{\text {b}}$ Student's $t$-test was performed on residual values adjusted for age and BMI

cThe formula for calculating LDL-C is described in "Subjects and methods", and we excluded subjects whose HDL-C or TG levels were $\geq 2.6 \mathrm{mM}$ or $4.53 \mathrm{mM}$, respectively (Control, $n=794$ : MI group, $n=403$ )

${ }^{\mathrm{d}}$ Student's $t$ test was performed on log-transformed residual values adjusted for age and BMI

for gender, we investigated only males. The T84C polymorphism was significantly associated with the incidence of MI (Table 7). Logistic analysis indicated that the frequency of $\mathrm{MI}$ in the CC genotype was lower than that in the CT + TT genotype $[P=0.0145$, $\mathrm{OR}=0.4955,95 \%$ CI: $0.2746-0.8525$, sample power $=0.75(\alpha$ value $=0.05$, two-tailed $)]$. Accordingly, subjects with the CC genotype had higher levels of HDL-C and were less susceptible to MI. However, multiple logistic analysis, which included hypertension (HT), DM, hyperlipidemia (HLP), smoking, and the T84C polymorphism, indicated that smoking $(P<0.0001)$, DM $(P<0.0001)$, HLP $(P=0.0003)$, and HT $(P=0.0339)$ were predictors of incidence of MI but that the T84C polymorphism was not a predictor $(P=0.0175)$.

\section{Discussion}

In the present study, we conducted a sequence analysis and detected nine polymorphisms in ApoA1. We evaluated the effects of eight polymorphisms, including four selected from the JSNP database, on the lipid profile using a large cohort representing the general population in Japan. We next confirmed the effects of the ApoAl 
T84C polymorphism on the HDL-C level in the MI group. Finally, we found a positive association between the ApoAl T84C polymorphism and the incidence of MI. However, this polymorphism was not an independent predictor when we performed the multiple logistic analysis, which included the established risk factors of smoking, DM, HLP, and HT.

The present study can be distinguished by three main features: an association study using a large cohort study in the general population (the Suita population), confirmation of the association using another set of subjects (the MI group), and the detection of a new protective marker for MI in the ApoAl gene.

As described previously (Zaman et al. 1997), the ApoA1 MspI and SstI polymorphisms were not associated with the levels of total cholesterol and HDL-C in the Shibata study, which represented the Japanese rural population. In the present study, we also did not observe an association between the ApoA1MspI [G(-310)A] polymorphism and HDL-C or TG levels. Since the ApoA1MspI polymorphism has only weak linkage with the ApoA1 T84C polymorphism $\left(r^{2}=0.0567\right.$, $P=0.0568$ ), the ApoA1 T84C polymorphism may have the greatest effect on the HDL-C level in the Japanese population.

The present study provides evidence that the ApoAI T84C polymorphism is associated with the incidence of MI. The ApoA1 T84C polymorphism may act in a proatherogenic or antiatherogenic fashion via the modulation of the HDL-C level because the ApoA1 polymorphisms have effects on the HDL-C level but not the LDL-C level. Yamada et al. reported that ApoA1 polymorphisms were weakly associated with the incidence of MI (Yamada et al. 2002), but they did not investigate the ApoA1 T84C polymorphism. Since the ApoA1 T84C polymorphism may have the greatest effect on the HDL$\mathrm{C}$ level in the Japanese population, it is possible that the ApoA1 T84C polymorphism may also most strongly influence the risk of MI in the Japanese population. Since the sample power was $0.75(\alpha$ value $=0.05$, twotailed), this study has adequate statistical power. However, the present association $(P=0.0145)$ was marginal. After adjustment of risk factors-smoking, DM, HLP, and HT - the significant association between the ApoAl T84C polymorphism and the incidence of MI was not observed. Contradictory results often occur in association studies due to ethnic differences or variations, including covariates such as gender and environmental factors. It has been recommended that a single nominally significant association should be viewed as tentative until it has been independently replicated at least once and preferably twice (Lohmueller et al. 2003). Accordingly, it will be necessary to verify the association between the ApoAl T84C polymorphism and the incidence of MI using another set of subjects.

The ApoA1 T84C polymorphism, an HaeIII restriction site, has recently been reported, and the frequency of the $\mathrm{T}$ allele of ApoA1 T84C in familial combined hyperlipidemia probands has been reported to be higher than in their spouses (Groenendijk et al. $2001 \mathrm{~b})$. It has been reported that individuals homozygous for the $\mathrm{T} 84 \mathrm{C}$ allele had higher TG and ApoCIII levels but not higher ApoA1 levels (Groenendijk et al. 2001b). Thus, it may be possible that this polymorphism could be in tight linkage with unknown polymorphisms located in exon or promoter regions in ApoAlor another genes.

We tried haplotype and diplotype analyses in the ApoAl gene. Since all of the polymorphisms were located on one haplotype block and the ApoA1 T84C polymorphism strongly influenced the levels of HDL and TG, we found no useful haplotype combination that was more influential than the ApoA1 T84C polymorphism.

The ApoA1 T84C polymorphism was associated with the TG level in the Suita population but not in the MI group. One possible reason for the different results between the Suita population and the MI group may be that a substantial proportion of the MI group had dyslipidemia and had been treated with hypolipidemic drugs. We could not retrospectively research who was treated with hypolipidemic drugs and what kind of hypolipidemic drug was used in patients with MI, because we made DNA sample anonymous. Accordingly, we did not have the ability to investigate the relationship between ApoA1 T84C and the lipid levels according to the drugs used drugs, such as statin or fibrate. Thus, another study is needed to confirm the genotype/drug interaction.

Our results indicated that three polymorphisms, ApoE genotype, ApoA1 T84C, and ABCA1 G(-273)C, were independently associated with the HDL-C level. Multiple components have been proposed to regulate the HDL-C level, including cholesterol ester transfer protein (CETP) (Barter et al. 2003), phospholipid transfer protein (Huuskonen et al. 2001), hepatic lipase (Deeb et al. 2003), lecithin cholesterol acyltransferase (Zhang et al. 2004), scavenger receptor class B type 1 (Hsu et al. 2003), endothelial lipase (Ma et al. 2003), ABC transporters, apolipoproteins, and several transcriptional factors. In Japanese, several polymorphisms such as CETP (Inazu et al. 1990) and ApoE (Zaman et al. 1997) were reported to be associated with the HDL-C level. Accordingly, a prospective study should be required to establish the contribution of the ApoAl T84C polymorphism on the HDL-C level and the incidence of MI.

In conclusion, the present results suggest that the ApoA1 T84C polymorphism significantly affects the HDL-C level in the general Japanese population and that this polymorphism may be a new risk marker for MI in Japanese.

Acknowledgements This study was supported by the Program for the Promotion of Fundamental Studies in Health Science of the Organization for Pharmaceutical Safety and Research of Japan. We are deeply grateful to Dr. Soichiro Kitamura, President of the National Cardiovascular Center, for his support of our research. We would like to thank Dr. Mitsuo Matsuda for stimulating 
discussions. We would also like to thank Dr. Otosaburo Hishikawa, Dr. Katsuyuki Kawanishi, and Mr. Shigeru Kobayashi for their continuous support of our population survey in Suita City. We also thank the members of the Satsuki-Junyukai.

\section{References}

Barter PJ, Brewer HB Jr, Chapman MJ, Hennekens CH, Rader DJ, Tall AR (2003) Cholesteryl ester transfer protein: a novel target for raising HDL and inhibiting atherosclerosis. Arterioscler Thromb Vasc Biol 23:160-167

Deeb SS, Zambon A, Carr MC, Ayyobi AF, Brunzell JD (2003) Hepatic lipase and dyslipidemia: interactions among genetic variants, obesity, gender, and diet. J Lipid Res 44:1279-1286

Groenendijk M, Cantor RM, de Bruin TW, Dallinga-Thie GM (2001a) The apoAI-CIII-AIV gene cluster. Atherosclerosis 157:1-11

Groenendijk M, Cantor RM, De Bruin TWA, Dallinga-Thie GM (2001b) New genetic variants in the apoA-I and apoC-III genes and familial combined hyperlipidemia. J Lipid Res 42:188-194

Hirakawa M, Tanaka T, Hashimoto Y, Kuroda M, Takagi T, Nakamura Y (2002) JSNP: a database of common gene variations in the Japanese population. Nucleic Acids Res 30:158-162

Hsu LA, Ko YL, Wu S, Teng MS, Peng TY, Chen CF, Chen CF, Lee YS (2003) Association between a novel 11-base pair deletion mutation in the promoter region of the scavenger receptor class B type I gene and plasma HDL cholesterol levels in Taiwanese Chinese. Arterioscler Thromb Vasc Biol 23:1869-1874

Huuskonen J, Olkkonen VM, Jauhiainen M, Ehnholm C (2001) The impact of phospholipid transfer protein (PLTP) on HDL metabolism. Atherosclerosis 155:269-281

Inazu A, Brown ML, Hesler CB, Agellon LB, Koizumi J, Takata K, Maruhama Y, Mabuchi H, Tall AR (1990) Increased highdensity lipoprotein levels caused by a common cholesteryl-ester transfer protein gene mutation. N Engl J Med 323:1234-1238

Jeenah M, Kessling A, Miller N, Humphries S (1990) G to A substitution in the promoter region of the apolipoprotein AI gene is associated with elevated serum apolipoprotein AI and high density lipoprotein cholesterol concentrations. Mol Biol Med 7:233-241

Kannel WB, Castelli WP, Gordon T (1979) Cholesterol in the prediction of atherosclerotic disease. New perspectives based on the Framingham study. Ann Intern Med 90:85-91

Karathanasis SK, Norum RA, Zannis VI, Breslow JL (1983) An inherited polymorphism in the human apolipoprotein A-I gene locus related to the development of atherosclerosis. Nature 301:718-720

Lefevre M, Ginsberg HN, Kris-Etherton PM, Elmer PJ, Stewart PW, Ershow A, Pearson TA, Roheim PS, Ramakrishnan R, Derr J, Gordon DJ, Reed R (1997) ApoE genotype does not predict lipid response to changes in dietary saturated fatty acids in a heterogeneous normolipidemic population. The DELTA Research Group. Dietary effects on lipoproteins and thrombogenic activity. Arterioscler Thromb Vasc Biol 17:2914-2923

Lohmueller KE, Pearce CL, Pike M, Lander ES, Hirschhorn JN (2003) Meta-analysis of genetic association studies supports a contribution of common variants to susceptibility to common disease. Nat Genet 33:177-182

Ma K, Cilingiroglu M, Otvos JD, Ballantyne CM, Marian AJ, Chan L (2003) Endothelial lipase is a major genetic determinant for high-density lipoprotein concentration, structure, and metabolism. Proc Natl Acad Sci USA 100:2748-2753

Maciejko JJ, Holmes DR, Kottke BA, Zinsmeister AR, Dinh DM, Mao SJT (1983) Apolipoprotein A-I as a marker of angiographically assessed coronary-artery disease. N Engl J Med 309:385-389

Mannami T, Konishi M, Baba S, Nishi N, Terao A (1997) Prevalence of asymptomatic carotid atherosclerotic lesions detected by high- resolution ultrasonography and its relation to cardiovascular risk factors in the general population of a Japanese city: the Suita study. Stroke 28:518-525

Marshall HW, Morrison LC, Wu LL, Anderson JL, Corneli PS, Stauffer DM, Allen A, Karagounis LA, Ward RH (1994) Apolipoprotein polymorphisms fail to define risk of coronary artery disease. Circulation 89:567-577

Matsunaga T, Hiasa Y, Yanagi H, Maeda T, Hattori N, Yamakawa K, Yamanouchi Y, Tanaka I, Obara T, Hamaguchi H (1991) Apolipoprotein A-I deficiency due to a codon 84 nonsense mutation of the apolipoprotein A-I gene. Proc Natl Acad Sci USA 88:2793-2797

Miller GJ, Miller NE (1975) Plasma-high-density-lipoprotein concentration and development of ischaemic heart-disease. Lancet $1: 16-19$

Ordovas JM, Schaefer EJ, Salem D, Ward RH, Glueck CJ, Vergani C, Wilson PWF, Karathanasis SK (1986) Apolipoprotein A-I gene polymorphism associated with premature coronary artery disease and familial hypoalphalipoproteinemia. N Engl J Med 314:671-677

Ordovas JM, Civeira F, Genest J Jr, Craig S, Robbins AH, Meade T, Pocovi M, Frossard PM, Masharani U, Wilson PWF, Salem DN, Ward RH, Schaefer EJ (1991) Restriction fragment length polymorphisms of the apolipoprotein A-I, CIII, A-IV gene locus. Atherosclerosis 87:75-86

Pagani F, Sidoli A, Giudici GA, Barenghi L, Vergani C, Baralle FE (1990) Human apolipoprotein A-I gene promoter polymorphism: association with hyperalphalipoproteinemia. J Lipid Res 31:1371-1377

Reguero JR, Cubero GI, Batalla A, Alvarez V, Hevia S, Cortina A, Coto E (1998) Apolipoprotein A1 gene polymorphisms and risk of early coronary disease. Cardiology 90:231-235

Shioji K, Mannami T, Kokubo Y, Inamoto N, Takagi S, Goto Y, Nonogi H, Iwai N (2004a) Genetic variants in PCSK9 affect the cholesterol level in Japanese. J Hum Genet 49:109-114

Shioji K, Nishioka J, Naraba H, Kokubo Y, Mannami T, Inamoto N, Kamide K, Takiuchi S, Yoshii M, Miwa Y, Kawano Y, Miyata T, Miyazaki S, Goto Y, Nonogi H, Tago N, Iwai N (2004b) A promoter variant of the ATP-binding cassette transporter A1 gene alters the HDL cholesterol level in the general Japanese population. J Hum Genet 49:141-147

Takagi S, Iwai N, Yamauchi R, Kojima S, Yasuno S, Baba T, Terashima M, Tsutsumi Y, Suzuki S, Morii I, Hanai S, Ono K, Baba S, Tomoike H, Kawamura A, Miyazaki S, Nonogi $\mathrm{H}$, Goto Y (2002) Aldehyde dehydrogenase 2 gene is a risk factor for myocardial infarction in Japanese men. Hypertens Res 25:677-681

Talmud PJ, Ye S, Humphries SE (1994) Polymorphism in the promoter region of the apolipoprotein AI gene associated with differences in apolipoprotein AI levels: the European atherosclerosis research study. Genet Epidemiol 11:265-280

Tuteja R, Tuteja N, Melo C, Casari G, Baralle FE (1992) Transcription efficiency of human apolipoprotein A-I promoter varies with naturally occurring $A$ to $G$ transition. FEBS Lett 304:98-101

Yamada Y, Izawa H, Ichihara S, Takatsu F, Ishihara H, Hirayama H, Sone T, Tanaka M, Yokota M (2002) Prediction of the risk of myocardial infarction from polymorphisms in candidate genes. N Engl J Med 347:1916-1923

Zaman MM, Ikemoto S, Yoshiike N, Date C, Yokoyama T, Tanaka $H$ (1997) Association of apolipoprotein genetic polymorphisms with plasma cholesterol in a Japanese rural population. The Shibata Study. Arterioscler Thromb Vasc Biol 17:34953504

Zhang K, Zhang S, Zheng K, Hou Y, Liao L, He Y, Zhang L, Nebert DW, Shi J, Su Z, Xiao C (2004) Novel P143L polymorphism of the LCAT gene is associated with dyslipidemia in Chinese patients who have coronary athrosclerotic heart disease. Biochem Biophys Res Commun 318:4-10 